\title{
Three Mn(II) complexes based on 6-(3-pyridyl)isophthalic acid ligand: structure modulation, stability and magnetic properties
}

Xiuling Zhang ${ }^{1,2}$, Na Wang ${ }^{1}$, Peng-Fei Liu ${ }^{1}$, Da-Shuai Zhang ${ }^{2}$, Hui $\mathrm{Hu}^{2} *$

${ }^{1}$ College of Chemical Engineering, Qingdao University of Science and Technology, Qingdao, 266000 P. R. China

${ }^{2}$ Key Laboratory of Coordination Chemistry and Functional Materialsin Universities of Shandong, College of Chemistry and Chemical Engineering, De Zhou University, De Zhou, 253023 P. R. China

Corresponding author. E-mail: dashuai_74@163.com and huhui723@126.com Tel: 0534-8985835.

\section{To Polyhedron}




\begin{abstract}
Based on the 6-(3-pyridyl)isophthalic acid ( $\mathrm{H}_{2}$ pip) ligand, three new complexes $\left[\mathrm{Mn}(\mathrm{Hpip})_{2}(\text { bipy })_{2}\left(\mathrm{H}_{2} \mathrm{O}\right)_{2}\right](\mathbf{1}),\{[\mathrm{Mn}(\text { pip })(\text { bibp })] \cdot \mathrm{DMA}\}_{\mathrm{n}}(\mathbf{2})$ and $[\mathrm{Mn}(\text { pip })]_{\mathrm{n}}(\mathbf{3})$, have been obtained under hydrothermal conditions and characterized by single-crystal X-ray diffraction. Compound $\mathbf{1}$ reveals a 0D mononuclear structure, and isolated molecules are further linked by hydrogen-bonds into a 3D supramolecular structure. In 2, the binuclear $\mathrm{Mn}_{2}(\mathrm{COO})_{4} \mathrm{~N}_{4}$ secondary building units (SBUs) are linked by neighboring ligands to result in a $2 \mathrm{D}$ layer structure. Inside of the structure of $\mathbf{3}$, one-dimensional (1D) chains are formed by the coordination of carboxylate groups and $\mathrm{Mn}^{2+}$, which are further connected by the ligands generating a 3D network. Notably, complex 3 reveals high thermal and aqueous stability, suggested by TGA and PXRD data. Moreover, the magnetic measurements indicate polymers $\mathbf{2}$ and $\mathbf{3}$ are both exhibit antiferromagnetic behavior.
\end{abstract}

\title{
Keywords
}

Coordination polymer; Synthesis; Crystal structure; Stability; Magnetic property 


\section{Introduction}

During the past few decades, the rational design and construction of coordination polymers (CPs) have been widely studied not only due to their fascinating structures and topologies but also the potential applications such as magnetism, gas storage, separation, catalysis, luminescence, ion exchange and so on [1-10]. However, it is still a big challenge to synthesize CPs more predictably and controllably at present, since the self-assembly of frameworks and final structures of polymers could be affected by too many factors, such as solvents, temperatures, $\mathrm{pH}$ value of the solution, ligand structures and so on [11-19]. As CPs are commonly obtained through the assembly of various organic ligands and inorganic secondary building units (SBUs, generally metal ions or metal-containing units), the exploitation of proper kinds of ligands is of great importance [20-22]. Among numerous kinds of organic ligands, carboxylate ligands with N-donors has been of specially interest in recent years. Their strong affinities with transitional metal ions and diverse coordination modes make them good candidates to construct CPs with various dimensional structures and interesting properties [23-26]. Our previous work showed that 6-(3-pyridyl)isophthalic acid $\left(\mathrm{H}_{2} \mathrm{pip}\right)$, as a ligand of this kind, have present various coordination modes and seemed to be a good choice [27].

On the other hand, because of the weak coordination bonding, many CPs are unstable when separated from their mother solution, which could limit their application. Therefore, to make CPs for practical utilization, stability of the framework is one of the key factors that could not be neglected, especially under tough conditions, for example, high temperature and aqueous environment [28-34].

In this paper, we utilized $\mathrm{H}_{2}$ pip as ligand and presented a series of $\mathrm{Mn}$ (II) complexes with structure dimension from $0 \mathrm{D}$, $2 \mathrm{D}$ to $3 \mathrm{D}$, namely, $\left[\mathrm{Mn}(\mathrm{Hpip})_{2}(\text { bipy })_{2}\left(\mathrm{H}_{2} \mathrm{O}\right)_{2}\right](\mathbf{1}),\left\{\left[\mathrm{Mn}\left(\text { pip }^{2-}\right)(\text { bibp })\right] \cdot \mathrm{DMA}\right\}_{\mathrm{n}}(\mathbf{2})$ and $[\mathrm{Mn}(\text { pip })]_{\mathrm{n}}(\mathbf{3})$, under hydrothermal conditions. Thermal and aqueous stability of complex $\mathbf{2}$ and $\mathbf{3}$ were investigated in this context. Furthermore, magnetic property were also studied, which show that compound $\mathbf{2}$ and $\mathbf{3}$ both reveal antiferromagnetic behavior. Herein, we report on the synthesis, crystal structures and properties of these complexes. 


\section{Experimental Section}

\subsection{Materials and General Methods}

All the chemical reagent of analytical grade were commercially available, and used without further purification. Powder X-ray diffraction (PXRD) data under the $2 \theta$ range $5-50^{\circ}$ were recorded using $\mathrm{Cu}-\mathrm{K} \alpha$ radiation $(\mathrm{k}=0.1542 \mathrm{~nm})$ on a Bruker D8A A25 X-ray diffractometer, with the X-ray tube operated at $40 \mathrm{kV}$ and $40 \mathrm{~mA}$ at room temperature. The Elementar Vario Micro Cube analyzer was used to carry out the elemental analyses $(\mathrm{C}, \mathrm{H}, \mathrm{N})$, and a SHIMADZU DTG-60 thermo analyzer was used to perform the thermogravimetric analyses (TGA) from room temperature to $800{ }^{\circ} \mathrm{C}$ under nitrogen protection with a heating rate of $20{ }^{\circ} \mathrm{C} \mathrm{min}^{-1}$. Infrared (IR) spectrum of the $\mathrm{KBr}$ disks dispersed sample powders were measured on a Thermo Nicolet IR 200 FT-IR spectrometer in the range of $4000-500 \mathrm{~cm}^{-1}$. Magnetic property were performed using a Quantum Design Squid-VSM magnetometer.

\subsection{X-ray Crystallography}

X-ray diffraction data for the single crystal sample of 1-3 were collected on a Bruker SMART APEXII CCD diffractometer equipped with a graphite monochromated Mo-K $\alpha$ radiation $(\lambda=0.71073 \AA)$. The SADABS programs was used to apply the empirical absorption correction [35]. Direct methods and full-matrix least-squares methods on $\mathrm{F}^{2}$ were performed to solve and refine the structure using the SHEXL 97 [36]. All the crystallographic programs were integrated into a system by using the single suite WINGX [37]. All non-hydrogen atoms were refined anisotropically. Geometrically calculations was implemented to locate the hydrogen atoms, and during the structure refinement, positions and thermal parameters of them were fixed as well. The crystallographic data and details of selected bond lengths and angles are summarized in Table 1 and Table S1, respectively.

\subsubsection{Synthesis of $\left[\mathrm{Mn}(\mathrm{Hpip})_{2}(\text { bipy })_{2}\left(\mathrm{H}_{2} \mathrm{O}\right)_{2}\right](\mathbf{1})$}

A mixture of $\mathrm{MnCl}_{2} \cdot 4 \mathrm{H}_{2} \mathrm{O}(0.0395 \mathrm{~g}, 0.2 \mathrm{mmol}), \mathrm{H}_{2}$ pip $(0.0243 \mathrm{~g}, 0.1 \mathrm{mmol})$ and 4,4'-Bipyridine (4,4'-bipy) (0.0156 g $0.1 \mathrm{mmol})$ were dissolved in distilled water (5 $\mathrm{ml}$ ) and then heated to $160{ }^{\circ} \mathrm{C}$ for $96 \mathrm{~h}$ in a $20 \mathrm{ml}$ stainless steel reactor with a Teflon 
liner. The reaction system was then cooled to room temperature slowly. Colorless block crystals of 1 were obtained with low yield and could hardly be purified.

\subsubsection{Synthesis of $\{[M n(\text { pip })(\text { bibp })] \cdot D M A\}_{n}(2)$}

A mixture of $\mathrm{MnCl}_{2} \cdot 4 \mathrm{H}_{2} \mathrm{O}(0.02 \mathrm{~g}, 0.1 \mathrm{mmol}), \mathrm{H}_{2}$ pip (0.006 g, $\left.0.025 \mathrm{mmol}\right)$ and 4,4'-Bis(imidazolyl)biphenyl (bibp) $(0.007 \mathrm{~g}, 0.025 \mathrm{mmol})$ were placed in a vial, followed by the addition of $1 \mathrm{ml} \mathrm{N}, \mathrm{N}^{\prime}$-dimethylacetamide (DMA) and $1 \mathrm{ml} \mathrm{H}_{2} \mathrm{O}$. The reaction system was sealed and then heated to $100{ }^{\circ} \mathrm{C}$ for $48 \mathrm{~h}$. After cooled to room temperature slowly, the reactor was unsealed and yellow block crystals of $\mathbf{2}$ formed. The obtained samples were finally filtered, washed with mother liquid and dried in air (yield: $49 \%$ based on $\mathrm{H}_{2}$ pip). $\mathrm{C}_{35} \mathrm{H}_{21} \mathrm{MnN}_{6} \mathrm{O}_{5}(\%)$ : Elemental anal. calcd. (\%) $\mathrm{C}$, 63.64; H, 3.20; N, 12.72. Found C, 63.62; H, 3.23; N, 12.69. IR frequencies (KBr, $\left.\mathrm{cm}^{-1}\right)$ : 1610(s), 1547(s), 1509(m), 1392(s), 1309(m), 1254(w), 1191(w), 1063(m), $835(\mathrm{w})$.

\subsubsection{Synthesis of $[M n(\text { pip })]_{n}(3)$}

A mixture of $\mathrm{MnCl}_{2} \cdot 4 \mathrm{H}_{2} \mathrm{O}(0.0395 \mathrm{~g}, 0.2 \mathrm{mmol})$ and $\mathrm{H}_{2}$ pip $(0.0243 \mathrm{~g}, 0.1 \mathrm{mmol})$ were placed in a $20 \mathrm{ml}$ stainless steel reactor with a Teflon liner, followed by the addition of distilled water $(5 \mathrm{ml})$. The reaction system was sealed and then heated to $160{ }^{\circ} \mathrm{C}$ for $96 \mathrm{~h}$. After cooled to room temperature slowly, the reactor was unsealed and colorless block crystals of $\mathbf{3}$ formed. The obtained samples were finally filtered, washed with $\mathrm{H}_{2} \mathrm{O}$ and dried in air (yield: $53 \%$ based on $\mathrm{H}_{2}$ pip). $\mathrm{C}_{13} \mathrm{H}_{7} \mathrm{MnNO}_{4}(\%)$ : Elemental anal. calcd. (\%) C, 52.72; H, 2.38; N, 4.73. Found C, 52.69; H, 2.39; N, 4.72. IR frequencies $\left(\mathrm{KBr}, \mathrm{cm}^{-1}\right)$ : 3437(s), 2343(w), 1635(m), 1376(w), 1109(m), 990(w), 785(w), 612(m), 552(m).

\section{Results and Discussion}

\subsection{Structural description}

$\left[\mathrm{Mn}(\mathrm{Hpip})_{2}(\text { bipy })_{2}\left(\mathrm{H}_{2} \mathrm{O}\right)_{2}\right]$ (1). Single-crystal X-ray diffraction analysis showed that complex 1 crystallized in the triclinic $P-1$ space group. In $\mathbf{1}$, each $\mathrm{Mn}(\mathrm{II})$ ion is six coordinated by two $\mathrm{O}$ atoms of carboxylate from two different pip ${ }^{2-}$ ligands, two $\mathrm{N}$ atom of pyridyl from two different 4,4'-bipy ligands and two $\mathrm{O}$ atoms from water 
molecules (Fig. 1a). However, each anionic pip ${ }^{2-}$ ligand bonds with one Mn(II) (Fig. 4a) using only one carboxylate group in a monodentate mode, and meanwhile, each 4,4'-bipy connects with only one $\mathrm{Mn}$ (II) as well by one of the pyridyl group. As a result, complex 1 shows a $0 \mathrm{D}$ mononuclear structure rather than infinite frameworks through coordination. These mononuclear molecules could be further joined together via two kinds of hydrogen bonds interactions (Fig. 1b and Table 2) (O-H...N, between the $\mathrm{O}-\mathrm{H}$ groups from coordinated water molecules and the $\mathrm{N}$ atoms from pyridyl of pip $^{2-}$ ligand; O-H...N, between the $\mathrm{O}-\mathrm{H}$ groups from carboxylate of the pip ${ }^{2-}$ ligands and the $\mathrm{N}$ atoms from pyridyl of 4,4'-bipy) into 3D supramolecular structures (Fig. 1c), though. The Mn-O bond distances are in the range of 2.1691(13)-2.2133(15) ( $\mathrm{A})$, and the Mn-N bond distance is 2.2976(16) ( $\mathrm{A})$. The bond angles between the donor atoms around the $\mathrm{Mn}(\mathrm{II})$ center range from 87.80(6) to 180.00(9) (deg) (Table S1).

(Insert Fig.1, Table 1, Table 2)

$\left\{[M n(\text { pip) }(\text { bibp })] \cdot D M A\}_{n}\right.$ (2). Structural analysis showed that compound 2 belongs to the $P-1$ space group of triclinic system. In complex 2 , there contains one independent $\mathrm{Mn}^{2+}$ center, one pip ${ }^{2-}$ ligand and one bibp ligand in the asymmetric unit. Every $\mathrm{Mn} 1$ cation is six-coordinated with a $\mathrm{MnN}_{2} \mathrm{O}_{4}$ octahedral geometry containing four carboxylate $\mathrm{O}$ atoms from three pip $^{2-}$ ligands and two imidazole $\mathrm{N}$ atoms from two bibp ligands (Fig. 2a). Each anionic pip ${ }^{2-}$ ligand bounds three $\mathrm{Mn}^{2+}$ ions (Fig. 4b). As shown in Fig. 2 (b), two adjacent $\mathrm{Mn}$ (II) are bonded together to generate a $\mathrm{Mn}_{2}(\mathrm{COO})_{4} \mathrm{~N}_{4} \mathrm{SBU}$, and each pip ${ }^{2-}$ ligand binds three SBUs to form a $1 \mathrm{D}$ chain with a ladder shape. These chains are further linked by bibp ligands generating the final $2 \mathrm{D}$ layer structure. Moreover, different layers are stacked together leading to the formation of 1D channels along $a$ axis, which were filled with DMA molecules. The effective free void volume is estimated to be $25.5 \%$ by PLATON [38] (402.8 $\AA^{3}$ out of the $1579.2 \AA^{3}$ per unit cell volume). Besides, the Mn-O bond distances are in the range of 2.099(2)-2.335(2) ( $\mathrm{A})$ while the $\mathrm{Mn}-\mathrm{N}$ bond distance is between 2.256(3)-2.272(3) ( $\AA$ ). The bond angles between the donor atoms around the $\mathrm{Mn}(\mathrm{II})$ center range from 57.37(7) to 167.96(10) (deg) (Table S1). 
$[M n(\text { pip })]_{n}$ (3). Structural analysis showed that compound $\mathbf{3}$ belongs to the $P 4_{3} 2{ }_{1} 2$ space group of tetragonal system. As shown in Fig. 3a, there contains one independent $\mathrm{Mn}^{2+}$ center and one pip ${ }^{2-}$ ligands in the asymmetric unit of 3. Every $\mathrm{Mn} 1$ cation is five-coordinated with a $\mathrm{MnNO}_{4}$ trigonal biyramid geometry containing four carboxylate $\mathrm{O}$ atoms from four $\mathrm{pip}^{2-}$ ligands and one pyridyl $\mathrm{N}$ atom from another pip ${ }^{2-}$ ligand. Each anionic pip ${ }^{2-}$ ligand bounds five $\mathrm{Mn}^{2+}$ ions (Fig. 4c), and the coordination of carboxylate groups with $\mathrm{Mn}^{2+}$ ions result in the formation of $1 \mathrm{D}$ metal chains, which are further linked by the ligands generating the final 3D framework [39] (Fig. 3b). The Mn-O bond distances are in the range of

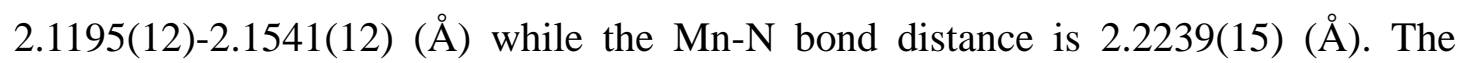
bond angles between the donor atoms around the $\mathrm{Mn}(\mathrm{II})$ center range from 84.63(5) to 179.84(6) (deg) (Table S1). Additionally, the effective free void volume is estimated to be only $1.7 \%$ by PLATON (38.4 $\AA^{3}$ out of the $2238.9 \AA^{3}$ per unit cell volume), indicating the low porosity of this compound.

\section{(Insert Fig.3)}

Structural modulation. From the above analysis, it could be seen that $\mathrm{H}_{2}$ pip ligand presents two different coordination types between compound $\mathbf{1}$ and $\mathbf{3}$. In $\mathbf{1}$, only one $\mathrm{O}$ atom participate in the coordination, and no $\mathrm{N}$ atoms coordinate with $\mathrm{Mn}^{2+}$ ions in the structure. As for $\mathbf{3}$, four $\mathrm{O}$ atoms and one $\mathrm{N}$ atoms all take part in the coordination with $\mathrm{Mn}^{2+}$ ions, forming a $\eta^{1}: \eta^{1}: \eta^{1}: \eta^{1}: \eta^{1}: \mu_{5}$ coordination mode. Possible reason for the structure differences of $\mathbf{1}$ and $\mathbf{3}$ with similar synthetic method but having completely different coordination mode, might be attributed to the addition of $\mathrm{N}$-donor ligand, 4,4'-bipy in $\mathbf{1}$, which could remarkably influence the coordination environment of $\mathrm{Mn}^{2+}$ ions and block the coordination between $\mathrm{Mn}^{2+}$ and $\mathrm{N}$ atoms from the $\mathrm{H}_{2}$ pip ligand. However, when adding bibp as auxiliary ligand at the same condition, no good crystals that are suitable for X-ray diffraction were obtained. Therefore, we changed the method into solvothermal reaction at low temperature, which resulted in the formation of $\mathbf{2}$. In the structure of $\mathbf{2}$, four $\mathrm{O}$ atoms from the two carboxylate groups of $\mathrm{H}_{2}$ pip ligand are all coordination atoms revealing a $\eta 1: \eta 1: \eta 1: \eta 1: \mu 3$ mode and no $\mathrm{N}$ atoms participate in the coordination. Moreover, 
through auxiliary ligand and reaction condition modulation, it finally led to the different structures of these compounds from OD mononuclear structure, 2D layer structure to $3 \mathrm{D}$ networks, which also demonstrating the various conformations of $\mathrm{H}_{2}$ pip in the assembly system.

(Insert Fig.4)

\subsection{TGA and PXRD}

Compound 2 with binuclear SBUs and 3 with internal metal chains encouraged us to evaluate its thermal and water stability. On one hand, TG analyses were performed to assess the thermal stability of compound $\mathbf{2}$ and $\mathbf{3}$. Before measurement, the samples were dried under $50{ }^{\circ} \mathrm{C}$ for several hours in order to remove the solvent of the surface. As shown in Fig. 5, the weight loss is $6.8 \%$ from 140 to $440{ }^{\circ} \mathrm{C}$ for compound 2, which is much lower than the calculated value for one DMA solvent molecule in the layers (13.2\%), indicating the removal of about one half DMA per formula unit (calcd 6.6\%). After $440{ }^{\circ} \mathrm{C}$, the structure of 2 begin to collapse, and the final $16.0 \%$ residue might be assigned to the formation of $\mathrm{MnO}$ (calcd 13.2\%). While no weight loss was observed for the pretreated samples of $\mathbf{3}$, indicating the complete removal of solvent molecules. Furthermore, TGA curve revealed that $\mathbf{3}$ could be stable up to about $460{ }^{\circ} \mathrm{C}$ which is a little higher than compound 2 , and then complex 3 starts to decompose. Finally, the $25.2 \%$ residue of the samples could be concluded to be the formation of $\mathrm{MnO}$ (calcd 24.0\%).

(Insert Fig.5)

One the other hand, PXRD patterns of compound 2 and $\mathbf{3}$ under different conditions were carried out, as shown in Fig. 6. Firstly, simulated PXRD patterns of 2 and 3 both agree well with their respective as-synthesized one, indicating the purity of the two compounds. After treated by soaking the samples into $\mathrm{EtOH}$ and boiling water for $72 \mathrm{~h}$, the main peaks of PXRD patterns for the two compounds could still match well with their simulated ones, respectively, although some slight changes were observed due to distortion of the crystal lattice in response to solvent exchanges, suggesting the good stability of $\mathbf{2}$ and $\mathbf{3}$ against solvents.

(Insert Fig.6) 


\subsection{Magnetic Properties}

Magnetic properties were measured on crystalline samples of compounds $\mathbf{2}$ and $\mathbf{3}$. In 2 , the obtained data suggests antiferromagnetic coupling between adjacent $\mathrm{Mn}^{\mathrm{II}}$ ions of one $\mathrm{Mn}^{\mathrm{II}}$ cluster and negligible $\mathrm{Mn}^{\mathrm{II}} \cdots \mathrm{Mn}^{\mathrm{II}}$ couplings between the neighboring Mn ${ }^{\text {II }}$ clusters. The obtained data indicates antiferromagnetic coupling between adjacent $\mathrm{Mn}^{\mathrm{II}}$ ions of one $\mathrm{Mn}^{\mathrm{II}}$ chain in $\mathbf{3}$ and negligible $\mathrm{Mn}^{\mathrm{II}} \cdots \mathrm{Mn}^{\mathrm{II}}$ couplings between the neighboring $\mathrm{Mn}^{\mathrm{II}}$ chains. The magnetic behaviors as detail discussed below.

The magnetism of $\mathbf{2}$ and $\mathbf{3}$ was studied by solid state magnetic susceptibility measurements in the $2-300 \mathrm{~K}$ range at a field of $1 \mathrm{kOe}$. The magnetic properties for 2 in the form of $\chi_{m} T v s . T$ and $\chi_{m}{ }^{-1} v s . T$ plots are shown in Fig. 7(a). The value of $\chi_{m} T$ at room temperature is $6.50 \mathrm{~cm}^{3} \cdot \mathrm{mol}^{-1} \cdot \mathrm{K}$, which is larger than the expected value $(4.375$ $\left.\mathrm{cm}^{3} \cdot \mathrm{mol}^{-1} \cdot \mathrm{K}\right)$ for one magnetically isolated $\mathrm{Mn}^{\mathrm{II}}$ ion $(\mathrm{S}=5 / 2, \mathrm{~g}=2.0)$. As the temperature decreases, the value of $\chi_{m} T$ slowly increases down to a $6.32 \mathrm{~cm}^{3} \cdot \mathrm{mol}^{-1} \cdot \mathrm{K}$ at $100 \mathrm{~K}$, while decreases rapidly below $100 \mathrm{~K}$ and reaches a minimum value of 0.72 $\mathrm{cm}^{3} \cdot \mathrm{mol}^{-1} \cdot \mathrm{K}$ at $2 \mathrm{~K}$. Mentioned above indicates antiferromagnetic coupling between adjacent $\mathrm{Mn}^{\mathrm{II}}$ ions of one $\mathrm{Mn}^{\mathrm{II}}$ cluster. Fitting the data at 2-300 $\mathrm{K}$ with the Curie-Weiss law $\left[\chi_{m}=C /(T-\theta)\right]$ gives $C=6.79 \mathrm{~cm}^{3} \cdot \mathrm{mol}^{-1} \cdot \mathrm{K}$ and $\theta=-8.34 \mathrm{~K}$. The small negative value of $\theta$ further confirms the overall antiferromagnetic couplings between neighboring $\mathrm{Mn}^{\mathrm{II}}$ ions. The $\chi_{m} T$ vs $T$ curve could be analyzed by equation 1 , which is based on the Hamiltonian: $\hat{H}=-2 J \hat{S}_{\mathrm{Mn} 1} \hat{S}_{\mathrm{Mn} 1 \mathrm{~A}}$.

$$
\begin{array}{cc}
\chi=\frac{N g^{2} \beta^{2}}{2 k T} \times \frac{10+35 A+84 B+165 C+286 e^{32 J / k T}}{4+6 A+8 B+10 C+12 e^{32 J / K T}} & \text { Equation 1 } \\
\chi_{m}=\frac{\chi}{1-\left(2 z j^{\prime} / N g^{2} \beta^{2}\right) \chi} & \text { Equation 2 }
\end{array}
$$

The best fitting gives $J=-0.60 \mathrm{~cm}^{-1}, g=1.80, z j^{\prime}=-0.06 \mathrm{~cm}^{-1}$. The $J$ value is reasonable and suggests weak antiferromagnetic interaction between the $\mathrm{Mn}^{\mathrm{II}}$ ions. It is noteworthy that the magnetic interactions between the adjacent $\mathrm{Mn}^{\mathrm{II}}$ clusters are negligible, attributing to the far distances of $\mathrm{Mn}^{\mathrm{II}} \cdots \mathrm{Mn}^{\mathrm{II}}$ ions. Therefore, complex 2 exhibits antiferromagnetic behavior. 
As for 3, the magnetic properties are presented in the form of $\chi_{\mathrm{m}} T v s T$ and $\chi_{\mathrm{m}}{ }^{-1} v s$ $T$ plots in Fig. 7(b). The resulted $\chi_{\mathrm{m}} T$ value is $4.22 \mathrm{~cm}^{3} \cdot \mathrm{mol}^{-1} \cdot \mathrm{K}$ at room temperature, which is slightly smaller than the theoretical value $\left(4.375 \mathrm{~cm}^{3} \cdot \mathrm{mol}^{-1} \cdot \mathrm{K}\right)$ for one magnetically isolated $\mathrm{Mn}^{\mathrm{II}}$ ion $(S=5 / 2, g=2.0)$. Along with temperature declining, the value of $\chi_{\mathrm{m}} T$ presents a slowly downward trend at the beginning with a decrease of only $0.23 \mathrm{~cm}^{3} \cdot \mathrm{mol}^{-1} \cdot \mathrm{K}$ at $100 \mathrm{~K}$, while a sharp decrease is observed below $100 \mathrm{~K}$ and it reaches a minimum value of $0.29 \mathrm{~cm}^{3} \cdot \mathrm{mol}^{-1} \cdot \mathrm{K}$ at $2 \mathrm{~K}$. Based on the above analysis, it reveals that antiferromagnetic coupling exists between adjacent $\mathrm{Mn}^{\mathrm{II}}$ ions of one $\mathrm{Mn}^{\mathrm{II}}$ chain. The data at $14-300 \mathrm{~K}$ was fitted by using the Curie-Weiss law $\left[\chi_{\mathrm{m}}=\right.$ $C /(T-\theta)]$, and the value of $C$ and $\theta$ was given as $4.48 \mathrm{~cm}^{3} \cdot \mathrm{mol}^{-1} \cdot \mathrm{K}$ and $-13.51 \mathrm{~K}$, respectively. As a result, the overall antiferromagnetic couplings could be further confirmed existing between neighboring $\mathrm{Mn}^{\mathrm{II}}$ ions by the negative value of $\theta$. It is noteworthy that the magnetic interactions between the adjacent $\mathrm{Mn}^{\mathrm{II}}$ chains are negligible, attributing to the far distances of $\mathrm{Mn}^{\mathrm{II}} \cdot \mathrm{Mn}^{\mathrm{II}}$ ions. Therefore, complex 3 also exhibits antiferromagnetic behavior.

(Insert Fig.7)

\section{Conclusions}

In summary, three novel complexes $\left[\mathrm{Mn}(\mathrm{Hpip})_{2}(\text { bipy })_{2}\left(\mathrm{H}_{2} \mathrm{O}\right)_{2}\right] \quad(\mathbf{1})$, $\{[\mathrm{Mn}(\mathrm{pip})(\mathrm{bibp})] \cdot \mathrm{DMA}\}_{\mathrm{n}} \quad$ (2) and $[\mathrm{Mn}(\mathrm{pip})]_{\mathrm{n}}$ (3) were constructed based on 6-(3-pyridyl) isophthalic acid $\left(\mathrm{H}_{2}\right.$ pip) and befitting metal salt under hydrothermal conditions. 1 displays a OD mononuclear structure. In 2, the binuclear $\mathrm{Mn}_{2}(\mathrm{COO})_{4} \mathrm{~N}_{4}$ secondary building units (SBUs) are linked by neighboring ligands to result in a 2D layer. Moreover, the contiguous 1D chains are interlinked through the carboxylate groups of the $\mathrm{H}_{2}$ pip ligands, extending the chains into 3D network in 3. Notably, complex $\mathbf{2}$ and $\mathbf{3}$ shows high performance on thermal and aqueous stability. Also, complexes $\mathbf{2}$ and $\mathbf{3}$ exhibit antiferromagnetic behavior.

\section{Acknowledgment}

This work was financially supported by the National Science Foundation of China (21371028, 21501022 and 21601028).

\section{Appendix A. Supplementary material}


CCDC 1483304 (for 1), CCDC 1524839 (for 2) and CCDC 1483353 (for 3) contain the supplementary crystallographic data for this paper. These data can be obtained free of charge via http://www.ccdc.cam.ac.uk/conts/retrieving.html (or from the Cambridge Crystallographic Data Centre, 12, Union Road, Cambridge CB2 1EZ, UK; fax: +44 1223 336033). 


\section{Reference}

[1] H.C. Zhou, J.R. Long, O.M. Yaghi. Chem. Rev., 112 (2012) 673.

[2] X.L. Zhang, P.F. Liu, N. Wang, D.S. Zhang. Polyhedron, 126 (2017) 83.

[3] B.A. Xiao, C.C. Chen. Chinese J. Inorg. Chem., 33 (2017) 347.

[4] H. Hu, F. Yang, R.H. Zhang, Y.H. Zhang, D.Y. Liu, G.M. Yang. J. Mol. Struct., 1036 (2013) 402.

[5] W.P. Ye, M. Chen, Y. Yang, L.Q. Zha, Y.S. Ma, R.X. Yuan. Chinese J. Inorg. Chem., 32 (2016) 1487.

[6] Q.Y. Li, Y. Quan, W. Wei, J. Li, H. Lu, R. Ni, X. J. Wang. Polyhedron, 99 (2015) 1.

[7] B. Zhai, L. Yi, H.S. Wang, B. Zhao, P. Cheng, D.Z. Liao, S.P. Yan. Inorg. Chem., 45 (2006) 8471.

[8] F.J. Yin, H. Zhao, X.Y. Xu, M.W. Guo. J. Coord. Chem., 66 (2016) 3199.

[9] S.J. Liu, S.D. Han, J.M. Jia, L. Xue, Y. Cui, S.M. Zhang, Z. Chang. CrystEngComm., 16 (2014) 5212.

[10] Y.H. Luo, C.Z. Tao, D.E. Zhang, J.J. Ma, L. Liu, Z.W. Tong. Polyhedron, 123 (2017) 69.

[11] Y.B. Xie, H. Yang, Z.U. Wang, Y.Y. Liu, H.C. Zhou, J.R. Li. Chem. Commun., 50 (2014) 563.

[12] P. Phuengphai, S. Youngme, P. Kongsaeree, C. Pakawatchai, N. Chaichit, S.J. Teat, P. Gamez, J. Reedijk. CrystEngComm., 11 (2009) 1723.

[13] N.N. Adarsh, P. Sahoo, P. Dastidar. Cryst. Growth Des., 10 (2010) 4976.

[14] J.P. Zhao, Y. Xie, J.R. Li, X.H. Bu, Dalton Trans., 45 (2016) 1514.

[15] C.H. Zhan, F. Wang, Y. Kang, J. Zhang. Inorg. Chem., 51 (2012) 523.

[16] J.P. Zhang, X.C. Huang, X.M. Chen. Chem. Soc. Rev., 38 (2009) 2385.

[17] Y. Ling, L. Zhang, J. Li, S.S. Fan, M. Du. CrystEngComm., 12 (2010) 604.

[18] G.R. Li, C.C. Xie, Z.R. Shen, Z. Chang, X.H. Bu, Dalton Trans., 45 (2016) 7866.

[19] Y. Zhang, X.B. Luo, Z.L. Yang, G. Li. CrystEngComm., 14 (2012) 7382.

[20] S.R. Batten, R. Robson. Angew. Chem. Int. Ed., 37 (1998) 1461.

[21] H. Kim, M.P. Suh. Inorg. Chem., 44 (2005) 810. 
[22] S.S.Y. Chui, S.M.F. Lo, J.P.H. Charmant, A.G. Orpen, I.D. Williams. Science, 283 (1999) 1148.

[23] H. Wu, H.Y. Liu, J. Yang, B. Liu, J.F. Ma, Y.Y. Liu. Cryst. Growth Des., 11 (2011) 2317.

[24] Q. Gao, Y.B. Xie, J.R. Li, D.Q. Yuan, A.A. Yakovenko, J.H. Sun, H.C. Zhou. Cryst. Growth Des., 12 (2012) 281.

[25] J.H. He, G.J. Zhang, D.R. Xiao, H.Y. Chen, S.W. Yan, X. Wang, J. Yang, E.B. Wang. CrystEngComm., 14 (2012) 3609.

[26] S.T. Zheng, T. Wu, C. Chou, A. Fuhr, P.Y. Feng, X.H. Bu. J. Am. Chem. Soc., 134 (2012) 4517.

[27] Y.Z. Zhang, X.L. Zhang, B.Y. Zhu, Y.E. Qiu, Z.W. Yuan. J. Inorg. Organomet Polym., 25 (2015) 635.

[28] D. Sun, Y. Ke, D.J. Collins, G.A. Lorigan, H.C. Zhou. Inorg. Chem., 46 (2007) 2725.

[29] X.L. Zhang, Y.Z. Zhang, D.S. Zhang, B.Y. Zhu, J.R. Li. Dalton Trans., 44 (2015) 15697.

[30] S.J. Yang, C.R. Park. Adv. Mater., 24 (2012) 4010.

[31] C. Yang, U. Kaipa, Q.Z. Mather, X. Wang, V. Nesterov, A.F. Venero, M.A. Omary. J. Am. Chem. Soc., 133 (2011) 18094.

[32] D.S. Zhang, Z. Chang, Y.F. Li, Z.Y. Jiang, Z.H. Xuan, Y.H. Zhang, J.R. Li, Q. Chen, T.L. Hu, X.H. Bu. Sci. Rep., 3 (2013) 3312.

[33] Y.Q. Chen, G.R. Li, Z. Chang, Y.K. Qu, Y.H. Zhang, X.H. Bu. Chem. Sci., 4 (2013) 3678.

[34] X.W. Zhu, X.P. Zhou, D. Li. Chem. Commun., 52 (2016) 6513.

[35] A.X.S. Bruker, SAINT Software Reference Manual, Madison. WI, USA, (1998) 243.

[36] G.M. Sheldrick. SHELXTL NT Version 5.1, Program for Solution and Refinement of Crystal Structures, University of GÖttingen, Germany, (1997) 246.

[37] L.J. Farrugia. J. Appl. Cryst., 32 (1999) 837. 
[38] A.L. Spek. PLATON, A Multipurpose Crystallographic Tool; Utrecht University: Utrecht, The Netherlands, (2006).

[39] S.J. Liu, S.D. Han, Z. Chang, X.H. Bu. New J. Chem., 40 (2016) 2680. 


\section{Captions to Figure and Tables}

Fig. 1 (a) Coordination environment of the Mn (II) in $\mathbf{1}$.

(b) The packing diagram of $\mathbf{1}$ showing the hydrogen bonding interactions. (pink dashed lines).

(c) 3D supramolecular structures formed by the hydrogen bonding interactions of 3. (pink dashed lines) ( $\mathrm{H}$ atoms omitted for clarity)

Symmetry codes: \#1 1-x, 1-y, 2-z

Fig. 2 (a) Coordination environment of the $\mathrm{Mn}(\mathrm{II})$ in 2.

(b) View of formation of 2D layer structure in compound 2. (H atoms omitted for clarity)

(c) View of the DMA-filled stacking channels of compound 2.

Symmetry codes: \#1 -x, 1-y, 2-z; \# 2 -1+x, y, 1+z; \#3 1-x, 1-y, 2-z;

Fig. 3 (a) Coordination environment of the $\mathrm{Mn}(\mathrm{II})$ in 3.

(b) 3D frameworks of $\mathbf{3}$ connected by $1 \mathrm{D}$ chains. (H atoms omitted for clarity)

Symmetry codes: \#8 1+x, y, z; \#9 3/2-y, 1/2+x, -1/4+z; \#10 1/2-x, -1/2+y, 7/4-z; \#11 x, y, 2-z

Fig. 4 Coordination modes of pip $^{2-}$ in 1-3: (a) for 1, (b) for 2 and (c) for 3.

Fig. 5 The TGA curves of compound $\mathbf{2}$ and $\mathbf{3}$.

Fig. 6 PXRD patterns of 2 (a) and 3 (b) and after being treated under different conditions for 72h.

(Simulated pattern derived from the X-ray single crystal data of compound $\mathbf{2}$ and $\mathbf{3}$ )

Fig. 7 Plots of $\chi m T$ vs. $T(\circ)$ and $\chi m^{-1}$ vs. $T(\diamond)$ (red part for the Curie-Weiss fitting) for 2 (a) and $\mathbf{3}$ (b).

Table 1 Crystal data and structure refinement parameters for compounds 1-3.

Table 2. Hydrogen bond lengths $(\AA)$ and bond angles $\left(^{\circ}\right)$ for compound $\mathbf{1}$. 
Fig. 1.

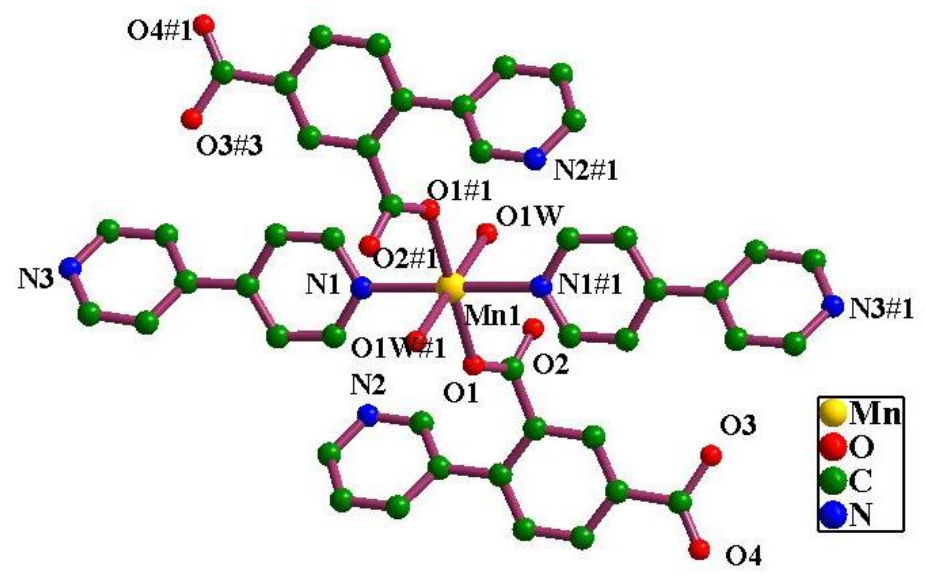

(a)

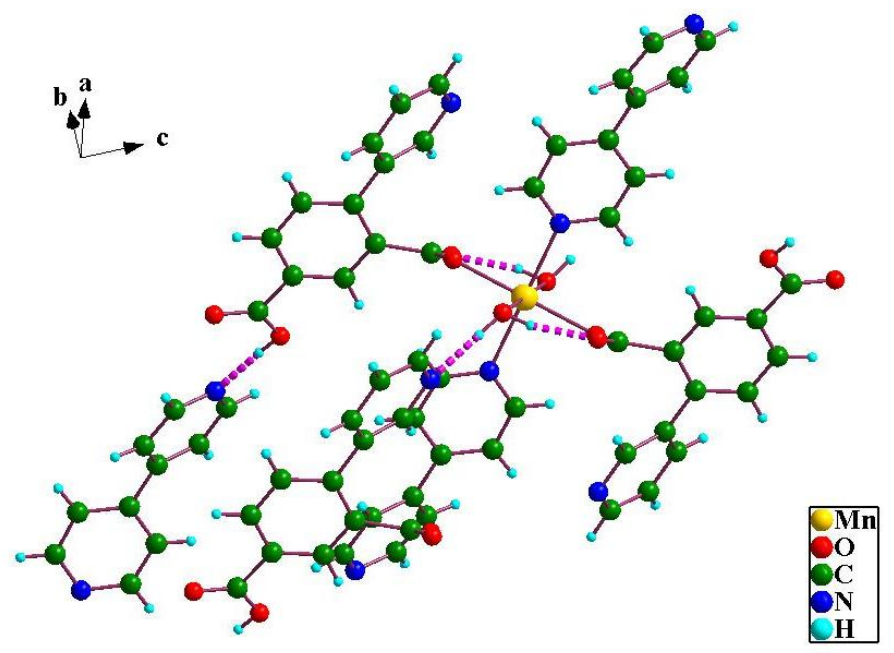

(b)

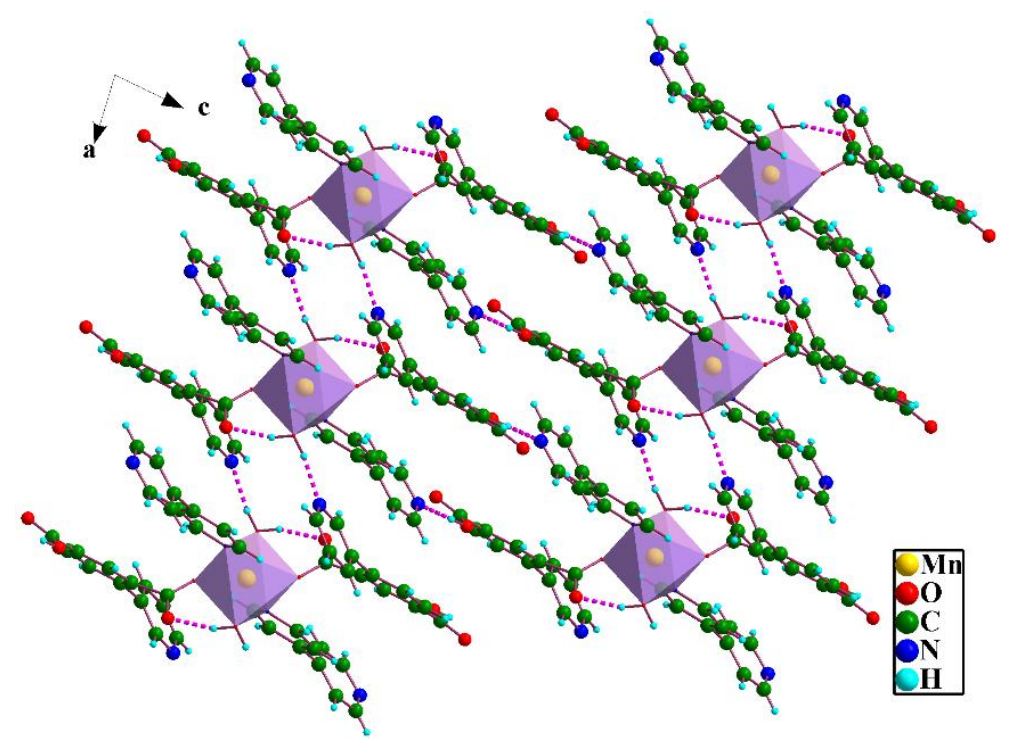

(c) 
Fig. 2.

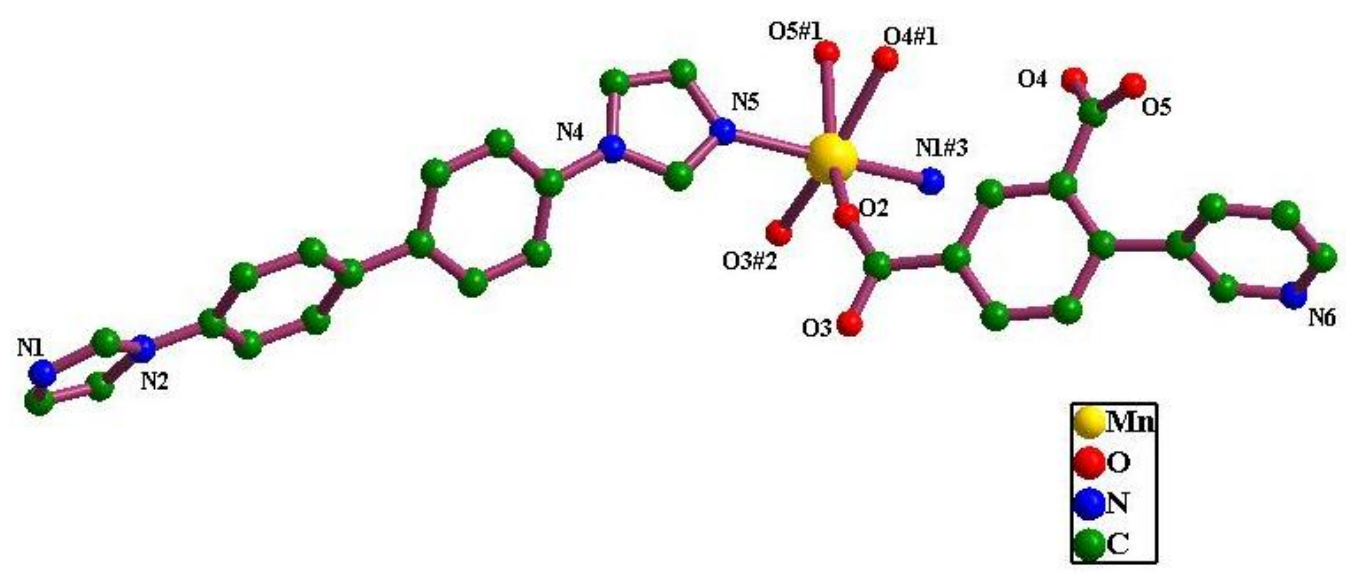

(a)

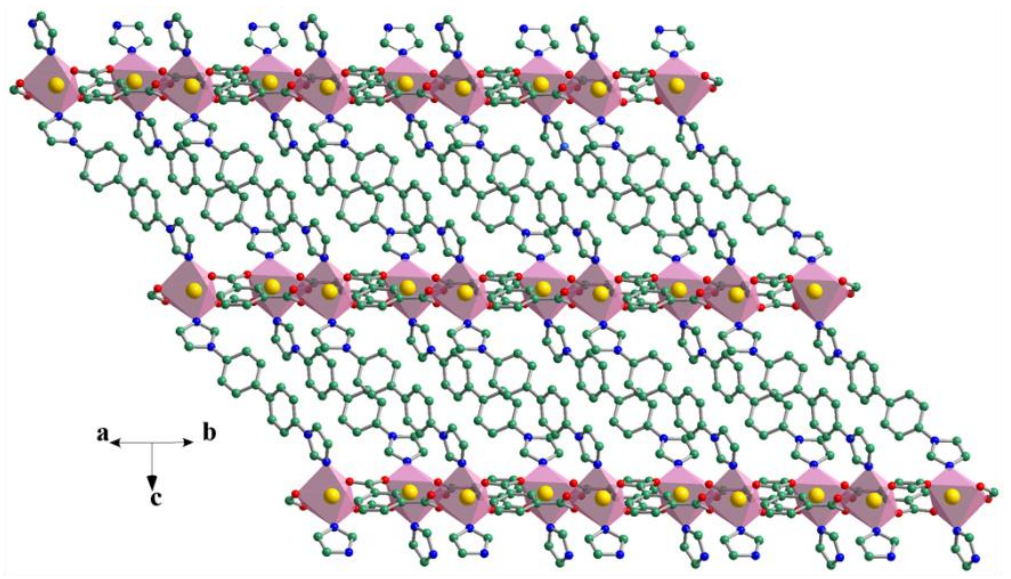

III

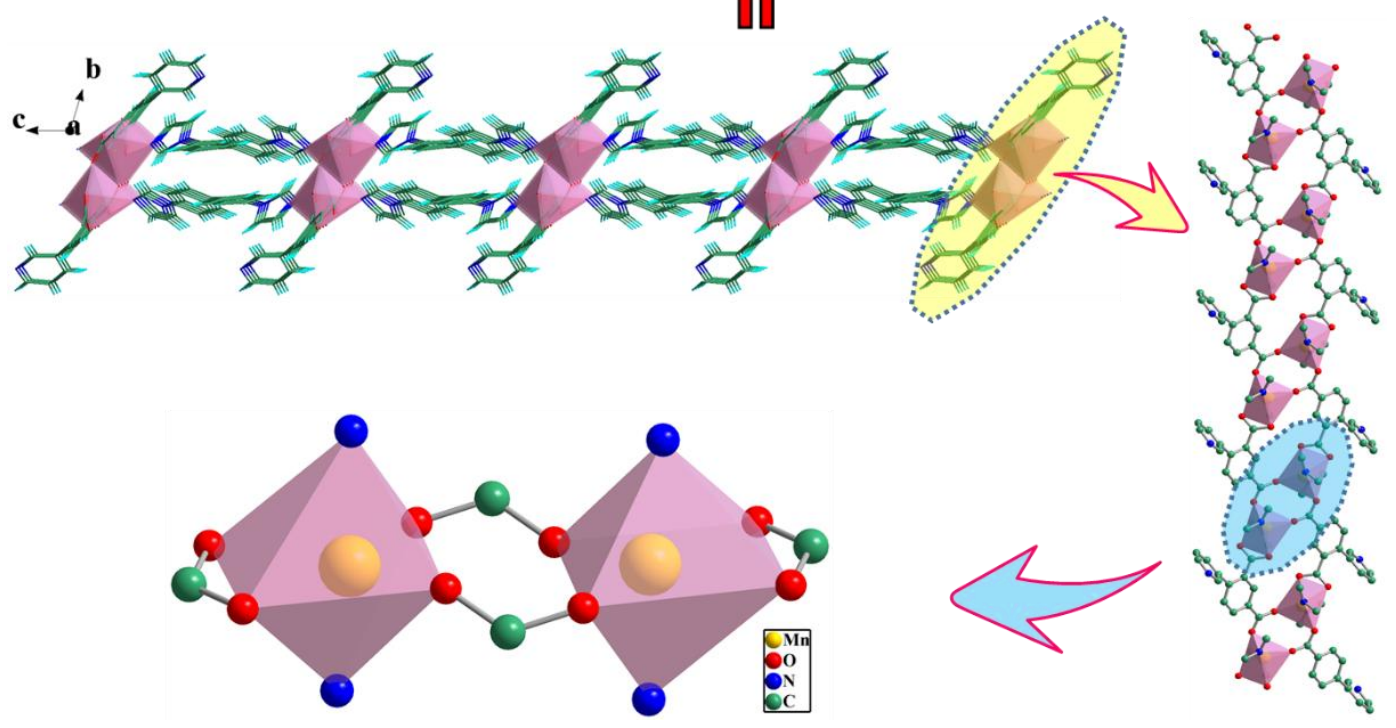

(b) 


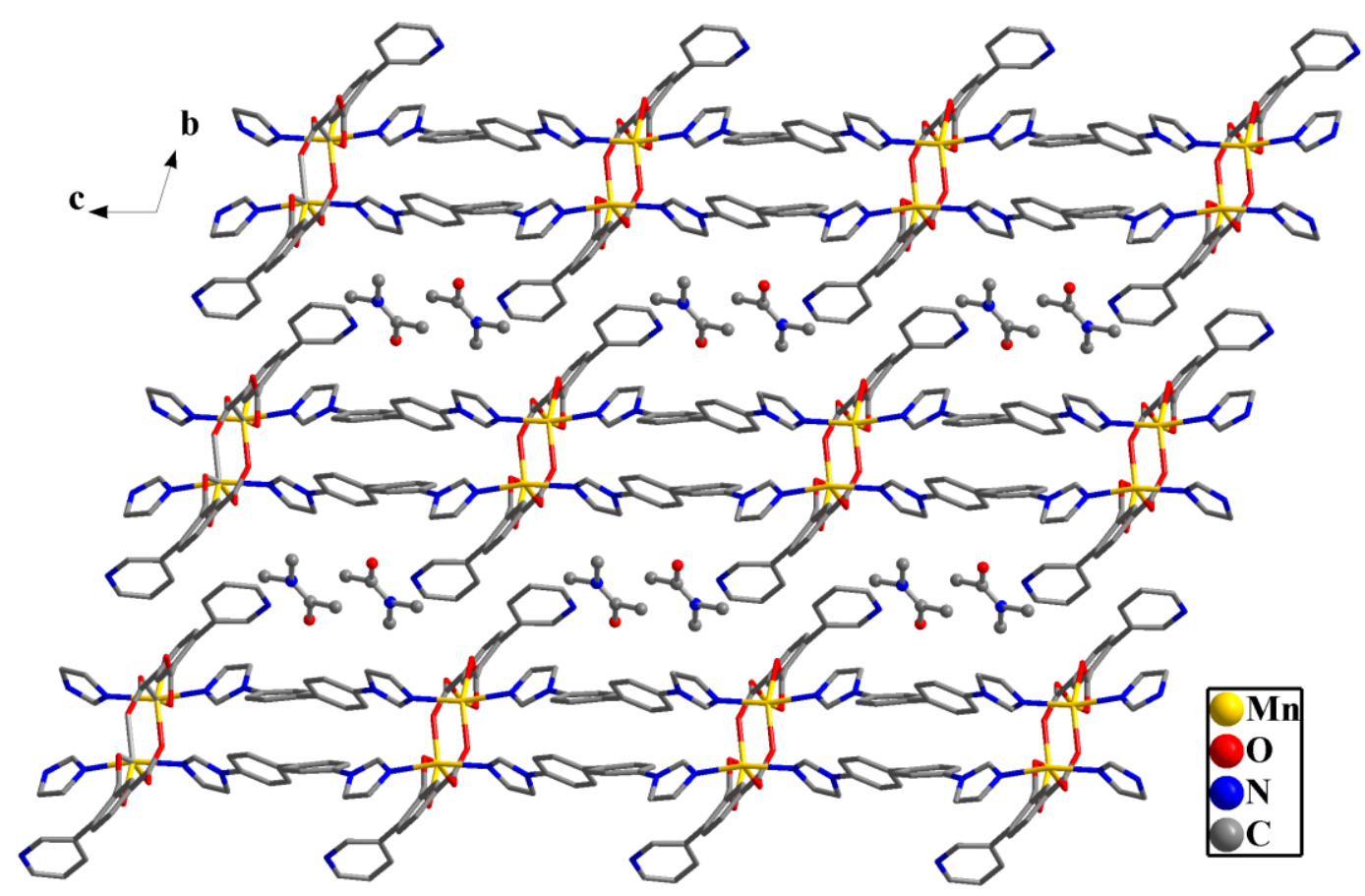

(c)

Fig. 3.

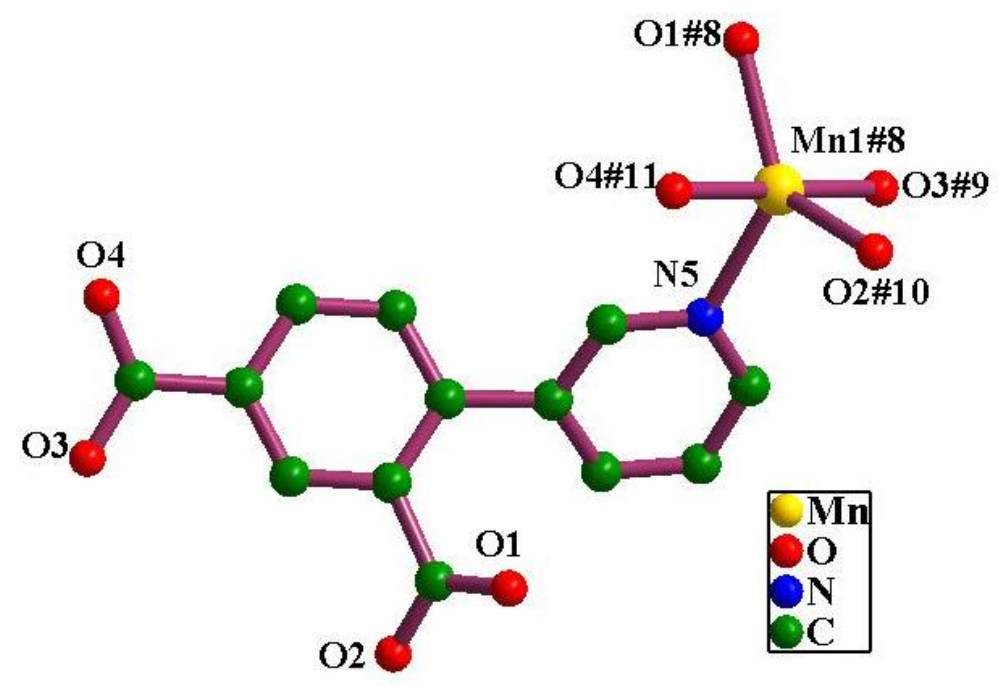

(a) 

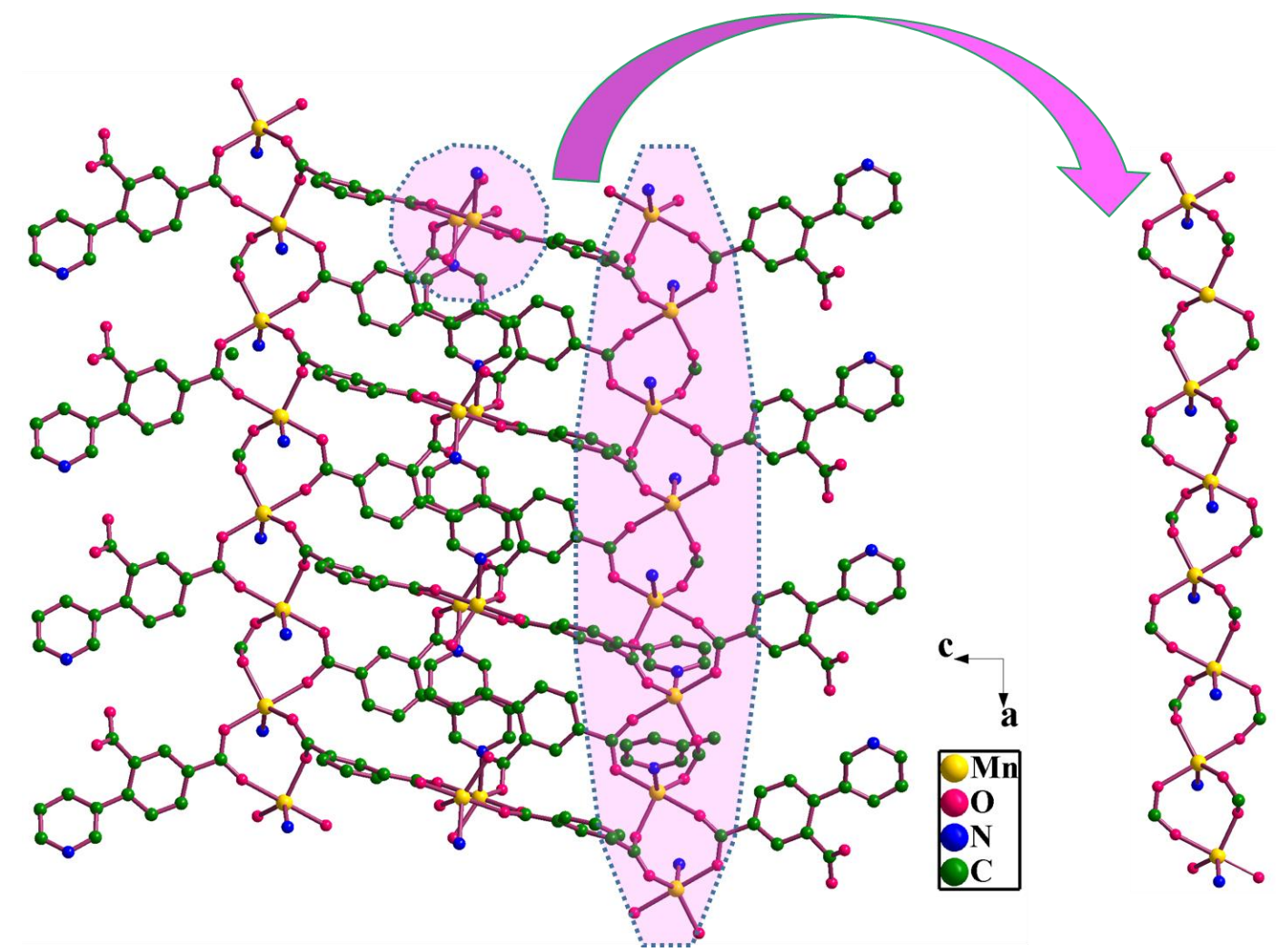

(b)

Fig. 4.

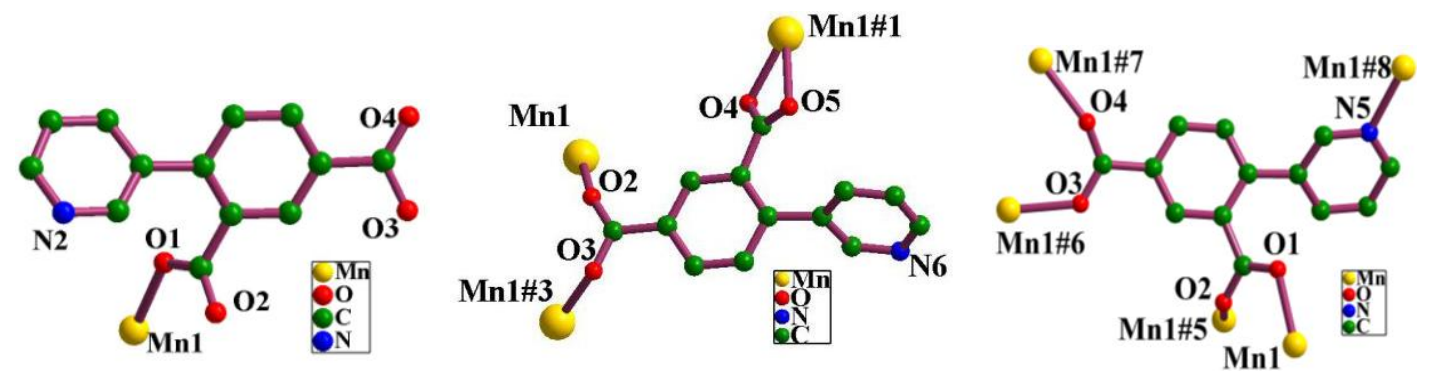

(a)

(b)

(c)

Fig. 5. 


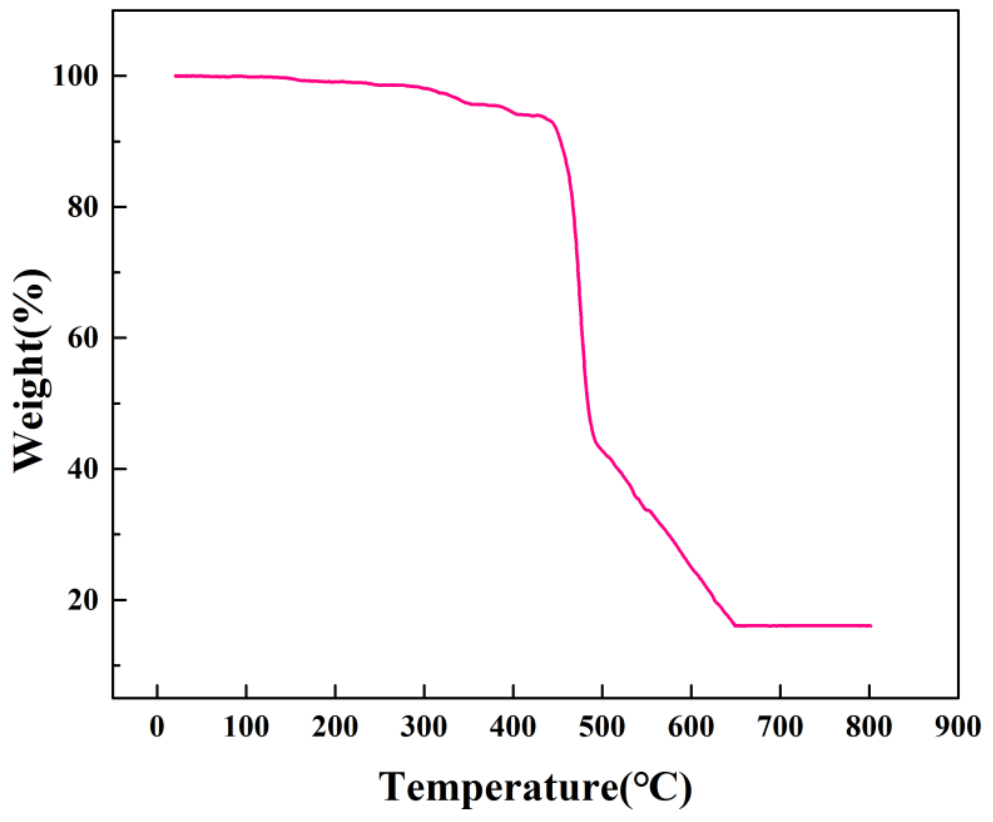

(a)

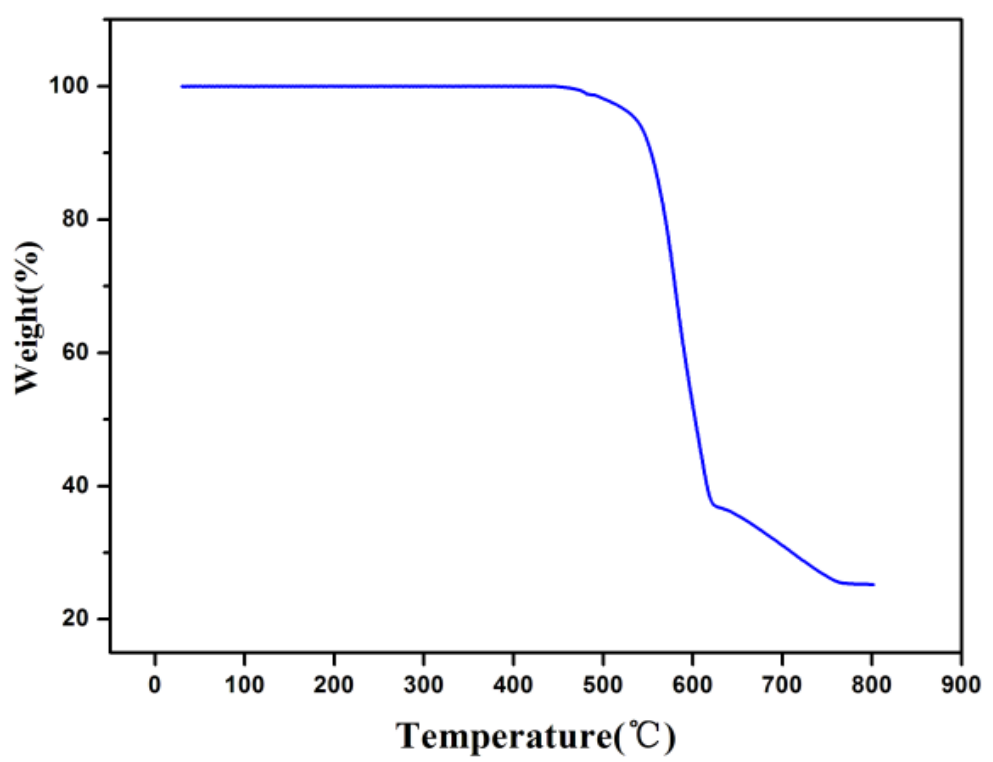

(b)

Fig. 6. 


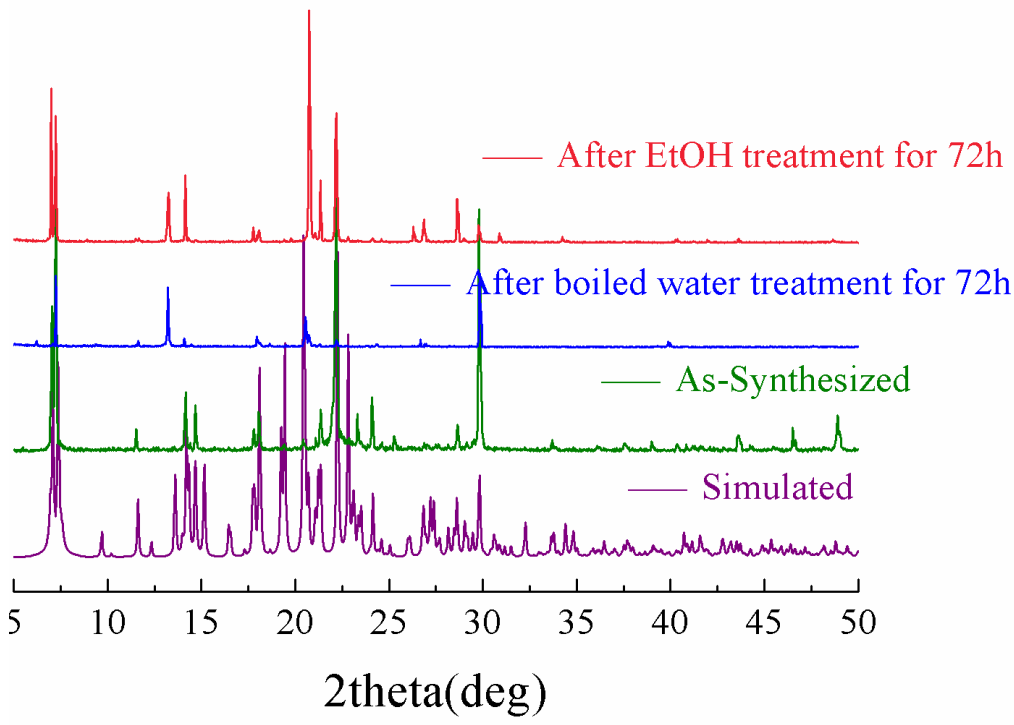

(a)
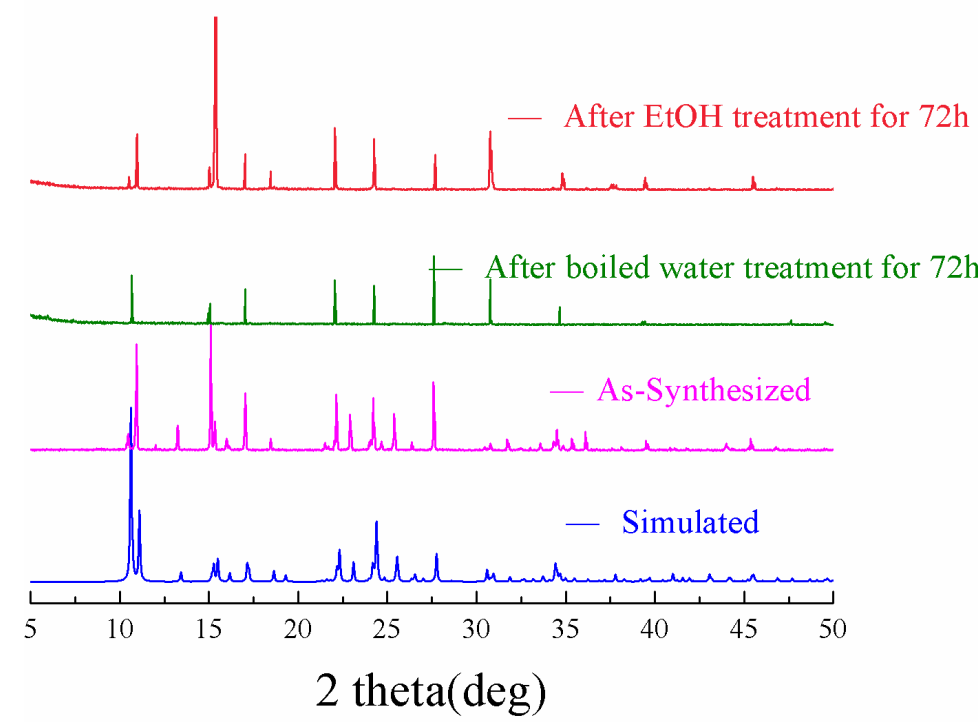

(b)

Fig. 7.

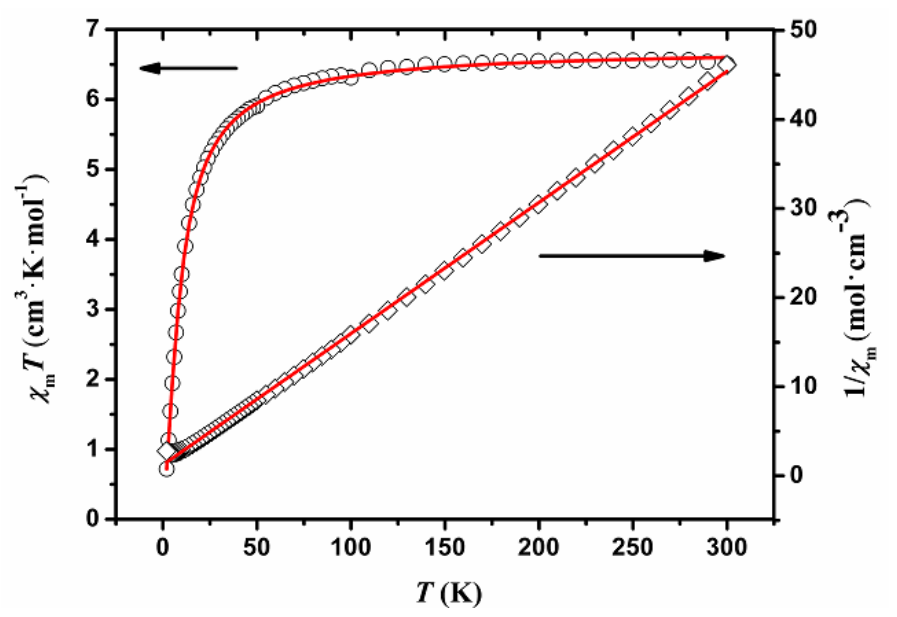


(a)

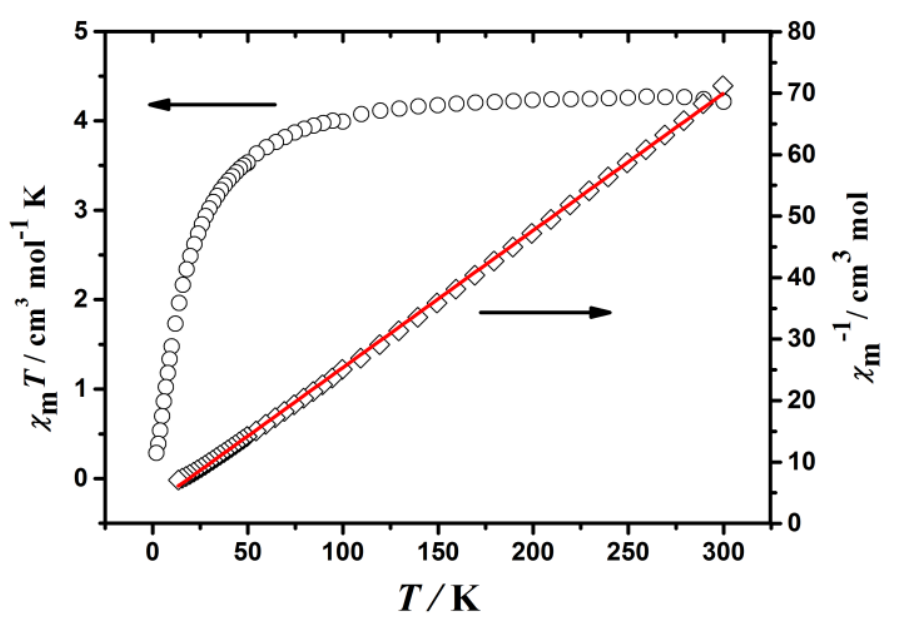

(b)

Table 1

\begin{tabular}{|c|c|c|c|}
\hline Compound & 1 & 2 & 3 \\
\hline Empirical formula & $\mathrm{C}_{46} \mathrm{H}_{36} \mathrm{MnN}_{6} \mathrm{O}_{10}$ & $\mathrm{C}_{35} \mathrm{H}_{21} \mathrm{MnN}_{6} \mathrm{O}_{5}$ & $\mathrm{C}_{13} \mathrm{H}_{7} \mathrm{MnNO}_{4}$ \\
\hline Formula weight & 885.73 & 660.52 & 296.14 \\
\hline Crystal system & monoclinic & triclinic & tetragonal \\
\hline Space group & $P-1$ & $P-1$ & $P 4_{3} 2_{1} 2$ \\
\hline \multicolumn{4}{|l|}{ Unit cell dimensions } \\
\hline$a(\AA)$ & $8.1130(10)$ & $10.129(6)$ & $8.2020(10)$ \\
\hline b $(\AA)$ & $9.2350(10)$ & $13.293(8)$ & 8.202 \\
\hline$c(\AA)$ & $14.8010(10)$ & $13.295(8)$ & $33.281(2)$ \\
\hline$\alpha(\operatorname{deg})$ & $83.9990(10)$ & $101.373(11)$ & 90 \\
\hline$\beta(\operatorname{deg})$ & $79.4700(10)$ & $101.661(11)$ & 90 \\
\hline$\gamma(\operatorname{deg})$ & $68.6890(10)$ & $109.825(10)$ & 90 \\
\hline Volume $\left(A^{3}\right)$ & $1014.84(18)$ & $1579.2(16)$ & 1757 \\
\hline $\mathrm{Z}$ & 1 & 2 & 8 \\
\hline $\begin{array}{l}\text { Calculated density } \\
\qquad\left(\mathrm{g} / \mathrm{cm}^{3}\right)\end{array}$ & 1.449 & 1.389 & 2.238 \\
\hline $\mathrm{F}(000)$ & 457 & 676 & 1192 \\
\hline $\begin{array}{c}\theta \text { range for data } \\
\text { collection }\left(^{\circ}\right)\end{array}$ & 2.37 to 27.48 & 3.26 to 53.94 & 2.45 to 27.47 \\
\hline
\end{tabular}




\begin{tabular}{cccc} 
Goodness-of-fit on $\mathrm{F}^{2}$ & 1.012 & 1.062 & 1.140 \\
Final R indices & $\mathrm{R} 1=0.0415$ & $\mathrm{R}_{1}=0.0520$ & $\mathrm{R}_{1}=0.0223$ \\
{$[\mathrm{I} 2 \mathrm{2} \sigma(\mathrm{I})]$} & $\mathrm{wR} 2=0.0898$ & $\mathrm{wR}_{2}=0.1334$ & $\mathrm{wR}_{2}=0.0608$ \\
& $\mathrm{R} 1=0.0596$ & $\mathrm{R} 1=0.0742$ & $\mathrm{R} 1=0.0227$ \\
$\mathrm{R}$ indices (all data) & $\mathrm{wR} 2=0.1004$ & $\mathrm{wR} 2=0.1486$ & $\mathrm{wR} 2=0.0610$ \\
$\begin{array}{c}\text { Largest diff. peak and } \\
\text { hole }\left(\mathrm{e} . \mathrm{A}^{-3}\right)\end{array}$ & 0.302 and -0.332 & 0.68 and -0.38 & 0.404 and -0.618 \\
\hline
\end{tabular}

Table 2

\begin{tabular}{llllll}
\hline & \multicolumn{1}{c}{$\mathrm{D}-\mathrm{H} \cdots \mathrm{A}$} & $\mathrm{d}(\mathrm{D}-\mathrm{H})$ & $\mathrm{d}(\mathrm{H} \cdots \mathrm{A})$ & $\mathrm{d}(\mathrm{D} \cdots \mathrm{A})$ & $<(\mathrm{DHA})$ \\
\hline Complex 1 & $\mathrm{O}(1 \mathrm{~W})-\mathrm{H}(1 \mathrm{~W}) \ldots \mathrm{O}(2)$ & $0.86(3)$ & $1.83(3)$ & $2.657(2)$ & $163(3)$ \\
& $\mathrm{O}(1 \mathrm{~W})-\mathrm{H}(2 \mathrm{~W}) \ldots \mathrm{N}(2) \# 2$ & $0.89(3)$ & $1.95(3)$ & $2.815(2)$ & $166(3)$ \\
& $\mathrm{O}(3)-\mathrm{H}(3 \mathrm{~S}) \ldots \mathrm{N}(3) \# 3$ & 0.82 & 1.83 & $2.645(2)$ & 176.9 \\
\multicolumn{5}{c}{ Symmetry codes: \#2-x+2,-y+1,-z+2 \#3 x,y-1,z-1 } \\
\hline
\end{tabular}

